\title{
Making Like Dolphins
}

\author{
John L. Simonds
}

Dolphins are noted for the consortial manner in which they make decisions about major actions. They mingle, they nudge each other, and they chatter for a long while until, at last, the group embarks on a common new activity. It works for them, so why not for the corporate world? Mimicking the dolphins, U.S. industry is now increasingly using a consortial process to address long-term issues such as high-risk, high-reward research.

Applied science by consortia of industrial and university organizations is a growing phenomenon in U.S. industry. Consortia have been established in almost every major American industry. Automotive, textile, semiconductor, digital recording, and power industries are a few of the major consortial efforts which have been established to date. There is even a super-level organization called the Council of Consortia Chief Executive Officers which has been established to share common information and procedures among dissimilar consortia. And, to no one's surprise, Japan has recently increased its support of this phenomenon with a rash of its own industrial consortial efforts.

The objective of some of the consortial groups is to perform long-term research by joint activities of industrial and university personnel. Sometimes the research is performed in a common location, but it is also common for each organization to do a portion of the research project in its own facilities and to coordinate with other members of the consortium through a designated management function. For example, the San Diego-based National Storage Industry Consortium (NSIC) provides administrative and accourting functions and even hires technical project managers to coordinate the work among its many participating members.

Two main actions of the government facilitated the creation of consortia: federal legislation permitting joint research among companies with freedom from certain types of litigation damages (i.e., treble damages), and governmental funding support provided through agencies such as the Department of Commerce's Advanced Technology Program (ATP) and Advanced Research Projects Agency (ARPA) in the Department of Defense. With these actions industrial/university teams developed to address high-risk, high-reward technical objectives which no single corporate entity could otherwise afford to undertake.

By any measure, these consortial efforts have had a beneficial effect on the participating organizations and their industries. While useful technology has been developed to aid American industries in a worldwide competitive arena, industries have also recognized exceptional value in the communications which déveloped among and between industries and universities during the consortial process.

NSIC, for example, which started in 1991, has a membership that now includes over 70 corporate and academic organizations with common interests in long-term research on digital recording technologies. Joint research programs are in progress and already yielding results that will continue to ensure worldwide competitiveness for its industrial members. Measured in terms of areal recording densities (the number of bits that can be stored in a unit area), the research points to improvements over the next decade of at least 100 times over current technology levels. And, in magnetic recording, for instance, success depends on extensive materials research on read/write heads and the tribology of the head-media interface.

But, lest you get the impression that this is all a piece of cake, three roadblocks to progress beleaguer the consortium organizers: lawyers, accountants, and the shifting sands of governmental support for consortial research. The first two impediments can be surmounted with persistence and patience. Lawyers and accountants in each organization are understandably reluctant to do anything which disrupts the normal internal workings of their organizations. The thoughts of sharing technical information and keeping related accounting records causes dyspepsia of the first order among these guardians of the corporate sanctity. Almost daily, consortia organizers receive calls from attorneys and accountants complaining that the joint research agree-

Material Matters is a forum for expressing personal points of view on issues of interest to the materials community. ments are "not in our standard language" or that the accounting data required is "not one of our standard forms". One small company even proposed that major companies revamp their entire accounting procedures so that they would be more compatible with that of the small company. Fortunately, upper managements realize the benefits of joint research and they often can be counted on to prevail upon their bean counters and legal squads to find acceptable ways to participate in consortial activities.

The problem of the fickleness of governmental support is not so easily dealt with. A prime example relates to current legislative actions which threaten to undermine ATP. This program has provided seed funding for joint research projects of a high-risk, high-reward nature which individual companies could not otherwise have funded by themselves. The ATP is only one of the governmental funding sources now termed by some legislators as "corporate welfare". Furthermore, there appears to be a strong feeling these days that governmental support should be given only to fundamental research, principally in universities and in national laboratories, which is not directed by industry or which aims to address a commercial need of that industry. Emphasis is being placed on new science with the hope that the results will eventually find a way to benefit commercial endeavors. It's a pendulum swing which may limit the ability of industry to provide clear focus targets for the new government-sponsored science.

The pendulum is in motion and, rather than flail at stopping it, U.S. industry has to pull up its socks and work together to find new ways to preserve the consortial process leading toward long-term technology developments. The benefits of joint research have been well-established. Industry has to provide more of its own funding to continue the process and, in many cases, to pay for critical university efforts which play such a vital role in the success of the work. No longer can individual corporations fund the extensive high-risk work that once was the backbone of industrial research. Only by sharing of critical resources can worldwide competitiveness be accelerated.

The fallout from this new approach is certain to be painful to both universities and industry. It will surely result in some redistribution of industrial support of universities. Universities will have to demonstrate a clear case for the critical contribution that they can make to industry-led long-term focus projects. Those university research centers which do not make this case convincingly may lose 
some of their current support from industry. Others may find a stronger movement toward industrial funding of designated project areas rather than blanket support of a very broad program. The focus areas will ideally be high-risk, highreward in nature and should result in the development of new science as well as applied technologies. Breakthroughs in fundamental science will hopefully also continue to be stimulated by governmen- tal support through agencies such as the National Science Foundation.

One aspect of this story will remain invariant: governmental support of research will continue to shift with time. Recognizing that, industry must emulate the dolphins more closely than ever. It's time for corporations and their university partners to gather together, chatter, honk at each other, and, finally, swim together on a path with long-term stability toward novel technologies. The consortial process is an effective route to the future, but the seas are rough these days and it's going to take a lot of resolve. Dolphins do itwhy can't we?

John L. Simonds, former Group Research Director for Eastman Kodak, founded the San Diego-based National Storage Industry Consortium in 1991. He has recently retired as Executive Director of NSIC, but continues to consult with the consortium and the industry.

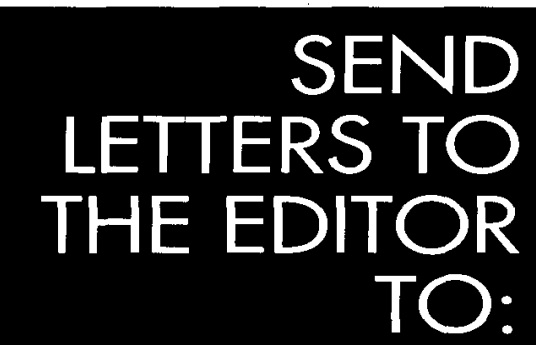

\section{MRS Bulletin}

9800 McKnight Road

Pittsburgh, PA 15237-6006

fax: (412) 367-4373

e-mail: Bulletin@mrs.org

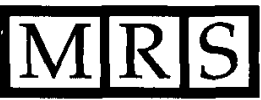

MATERIALS

RESEARCH

SOCIETY

Letters must include your full name, institution, address, and phone number.

- Worldwide distribution.

- EPA approved facility with toll refining capabilities.

DOT/MTA certitied packaging.

High purity customized containers and valving.

Unsurpassed product quality and reliability.

Eagle-Pleher Industries, Inc., Electro-Oplic Materials Department P.O. Box 737. Quapaw, OK 74363 (918) 673-1650 FAX: (918) 673-2121

Eaglo-Picher Matorials GmbH. Postfach 15 49, D-74605 Ohringen, Germany 49-7941-9134-0 FAX: 49-7941-9134-16

Yamanaka Hutech, 20 Toderacho Ohara. Sakyo-ku Kyoto, Japan 601-12 81-75-744-2011 FAX: 81-75-744-3157 in the world, only one delivers 150 years of experience with every order.

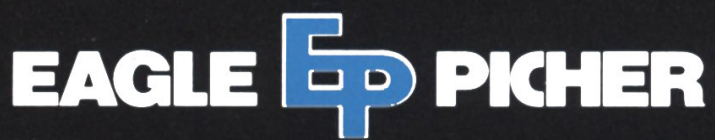

Cirelo No. 15 on Reader Sarvice Card. 


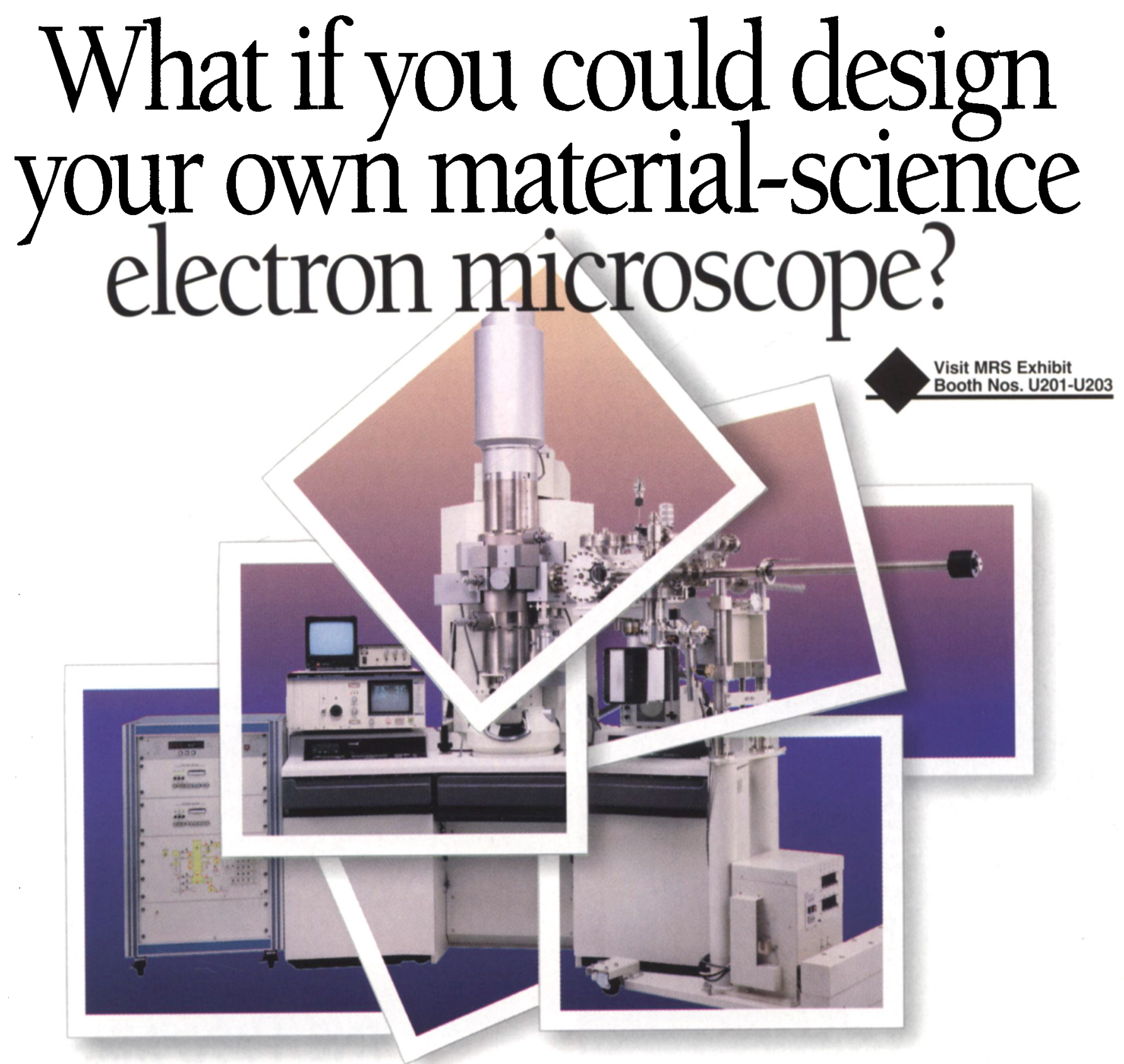

Chances are it would be like one of our fully computerized H-8100 or H-9000 Series instruments. Because you know "one model fits all" solutions aren't solutions at all. So you'd seek versatility and expandability in a microscope suited to current and anticipated needs.

Our $\mathrm{H}-8100$, for example, is a $200-\mathrm{kV}$ workhorse for high-resolution work and analytical applications. It delivers crystal lattice resolution to $.14 \mathrm{~nm}$ and, in TEM mode, lets you apply a high probe current in a 1-nm probe for nm-area X-ray and EELS analysis. The patented linear actuated design of its Hiper-Stage ensures stabil- ity, accuracy and reliability. And the turbomolecular pump (TMP) and column-baking mode mean fast pumpdowns and clean vacuum conditions.

For higher resolution and magnification in a compact microscope, one of our $300-\mathrm{kV} \mathrm{H}-9000$ TEMs is the answer. The H-9000UHR delivers $1.0 \AA$ lattice capability. For ultra-high vacuum, there's the H-9000UHV with a TMP/ ion pump combination that allows $10^{-10}$ Torr-without nitrogen. And for extended flexibility in EDS work, our H-9000NAR offers maximum sensitivity and precise quantitative analysis.
Better call or write for details. See how our H-8100/9000 instruments can provide just what your work demands. No near misses, no compromises, no costly overkill And, after all, isn't that how you'd design your microscope?

\section{HITACHI \\ SCIENTIFIC INSTRUMENTS}

Nissei Sangyo America, Ltd.

755 Ravendale Drive

Mountain View, CA 94043

(415) 969-1100

25 West Watkins Mill Road Gaithersburg, MD 20878

(301) $840-1650$ 